\title{
Organic Farming for Sustainable and Nutritional Fruit Production in India: A Review
}

\author{
Kuldeep Singh ${ }^{1}$, Sunil Kumar ${ }^{1}$, Satyabrata Pradhan ${ }^{1}$ and Om Prakash Patidar ${ }^{2 *}$ \\ ${ }^{1}$ Division of Fruits and Horticultural Technology, ICAR-Indian Agricultural Research \\ Institute, New Delhi, India \\ ${ }^{2}$ Division of Genetics, ICAR-Indian Agricultural Research Institute, New Delhi, India
}

*Corresponding author

\section{A B S T R A C T}

\begin{tabular}{|l|}
\hline Ke y w o r d s \\
$\begin{array}{l}\text { Organic, Fruit, } \\
\text { sustainable, Bio- } \\
\text { fertilizers, Manure, } \\
\text { Biological }\end{array}$ \\
\hline Article Info \\
\hline $\begin{array}{l}\text { Accepted: } \\
\text { 22 April } 2018 \\
\text { Available Online: } \\
\text { 10 May } 2018\end{array}$ \\
\hline
\end{tabular}

During green revolution intensive use of chemical in agriculture might have helped to achieve a dramatic increase in crop yield ensuring food security in India, but meanwhile, the intensive application of chemical fertilizers and pesticides led to gradual decline in soil health and environment, and food safety became a major concern. This has raised question regarding the sustainability of agriculture/horticulture in the long term, urging attention towards sustainable production practices. Accepting the harmful effect of the excessive use of chemical fertilizers on soil health and pesticides on human health, there is a need for an integrated management system. Organic farming can provide quality food without adversely affecting the soil's health and the environment, thus may be one of the options for sustainability. Organic food is not only attractive but also associated to quality, healthy and natural products in opposition to the more processed and conventional food. The paper has been reviewed for organic fruit production with sustainable approach in horticulture in India.

\section{Introduction}

Rapid increase of human population together with global climate variability resulted in increased demand of plant based food and energy sources (Varshney et al., 2011). Fruits have essential role to enhance quality of humankind life since a diet based on cereal grains, root and tuber crops, and legumes is generally lacked a wide range of products such as fiber, vitamin, provitamins or other micronutrients and compounds exist in fruit crops (Heslop-Harrison, 2005). Fruits are one the major sources of micronutrients (e.g. vitamins and minerals), phytonutrients (e.g. antioxidants) and dietary fibers that are essential for human health (Klee, 2010). Owing to their commercial value and source of many processed food or secondary products, fruits play a key role in the economy of many developing countries. India is the second largest producer of fruits in the world, after China with a production of 91.7 million metric tons of during 2016-17. Rapid growth in fruit production has been accompanied by heavy use of pesticides and chemical fertilizers. The increased use of chemical pesticides and fertilizers on fruit crops has 
raised a number of economic, ecological and health concern. Several technologies such as greater use of synthetic agrochemicals like fertilizers and pesticides, adoption of nutrientresponsive, high-yielding varieties, greater exploitation of irrigation potentials etc. has boosted the fruit production in the country. However, Profitability of the fruit industry is directly correlated with production of improved quality of fruits. Therefore, for sustaining the productivity of the crop, maintaining the soil health and healthy ecosystem, there is need for adoption of an alternative farming system, may be the organic farming. India has converted 6.0 million ha of cultivated land into organic and another 1.17 million ha are under conversion (Yadav, 2012). As per the available statistics, India's rank in terms of World's Organic Agricultural land was 15 as per 2013 data (Source FIBL \& IFOAM Year Book 2015). The total area under organic certification is 5.71million Hectare (2015-16). This includes $26 \%$ cultivable area with 1.49 million Hectare and rest $74 \%$ (4.22 million Hectare) forest and wild area for collection of minor forest produces. India produced around 1.35 million MT (2015-16) of certified organic products which includes all varieties of food products namely Sugarcane, Oil seeds, cereals and millets, cotton, pulses, medicinal plants, tea, fruits, spices, dry fruits, vegetables, coffee etc. The production is not limited to the edible sector but also produces organic cotton fiber, functional food products etc. Among all the states, Madhya Pradesh has covered largest area under organic certification followed by Himachal Pradesh and Rajasthan.

Organic farming is defined as a holistic production management system which promotes and enhances agro-ecosystem health, including biodiversity, biological cycles, and soil biological activity (FAO) or Organic agriculture is a production system that sustains the health of soils ecosystems and people (IFOAM) or Organic farming is a production system that excludes the use of synthetically produced fertilizers, biocides, growth regulators, and livestock feed additives such as antibiotics and growth hormones (USDA). Thus, besides the fact that no synthetic fertilizers and chemical pesticides are used in organic farming, there is a general idea that organic farming contributes to improved human and environmental health.

Organic farming is a method of farming system, which primarily aims at cultivating the land and raising crops in such a way, so as to keep the soil alive and in good health. In the Indian context organic farming is also termed as "Javik Krishi".

\section{Rise of organic fruit production}

As mentioned above, organic farming is one approach to increasing sustainability in agriculture that is market-driven and growing rapidly. The origins of organic farming come from a focus on improving organic matter in the soil in order to grow healthy plants that can resist pests and diseases, and that provide maximum health to the people and animals that eat them. One guiding principle is the use of natural materials for crop production and the avoidance of synthetic materials (e.g. fertilizers, pesticides). Another principle is to work with the natural systems and processes as much as possible, concurring with the 'Nature as model' idea of Wes Jackson and others. Thus, organic farming shares virtually all the goals articulated by sustainable agriculture proponents. As organic farming expanded in the 1980s, certification programs became necessary to guarantee to the consumer that the product they were buying, and generally paying a higher price for, was indeed produced as they expected. The 'no chemicals' or 'no synthetics' principles were often the strongest impressions in the consumer mind. Organic certification 
programs can more easily determine if a grower has or has not used a particular material than they can verify that a farm is 'working with natural systems.' As a result, much of the focus of organic certification has been on determining what materials are allowed for use on organic farms. Sustainable agriculture generally does not share this focus, although IFP programs often do exclude or restrict the use of certain more toxic or disruptive pesticides.

Organic matter, a key consideration in organic agriculture, is arguably the most important aspect of sustainable soil management. Tillage is a practice that can quickly degrade organic matter. Since tree fruit and vine systems are perennial and typically involve little tillage after planting, they can be very conducive to increasing soil organic matter. On the other hand, tree fruit and vine crops typically require a high level of pest management to produce marketable crops. Organic growers are greatly restricted in the pest control products they can use.

The allowed products are generally less effective and of shorter duration than products that growers following other production approaches, including IFP, can use. Key challenges for organic fruit production include nutrient management, weed control, and control of plant diseases.

\section{Component of organic farming}

The term organic is best thought of referring not to the type of inputs used, but to the concept of the farm as an organism, in which all the components likes, soil minerals, organic matters, microorganisms, insects, plants, animals and humans interact to create coherent, self-regulating and stable whole. Reliance on external inputs, whether chemical or organic, is reduced as far as possible. Organic farming is holistic production system.

\section{Organic manure}

Composting, generally defined as the biological aerobic transformation of an organic by-product into a different organic product that can be added to the soil without detrimental effects on crop growth. The composting process can result in obtaining stable humus and humic and fulvic acids, characterized by a high nutritional value and potential for fertilization of soils with nutriment deficiencies. The benefits provided by composts are broad and can be of a physical, chemical, biological, or environmental nature. Application of compost depends on the condition of the organic matter, moisture content, temperature, the $\mathrm{pH}$ and presence of microorganisms in the compost pile. For example, composts improve drainage and absorption of moisture in soils with structural deficiencies or lack of nutrients. They also make it possible to 1) increase crop productivity, 2) promote plant growth by incorporating essential nutrients, 3) facilitate implementation in different types of soil, 4) reduce runoff, and 5) obtain economic benefits for farmers. Adding organic composts to apple orchard soils has been shown to improve the blooming and growth of newly planted trees and fruit yields.

\section{Bio-fertilizer}

Biofertilizer is a substance which contains living microorganism which, when applied to seed, plant surfaces, or soil, colonizes the rhizosphere or the interior of the plant and promotes growth by increasing the supply or availability of primary nutrients to the host plant. Biofertilizer plays very significant role in improving soil fertility by fixing atmospheric nitrogen both in association with plant roots and without it. It also solubilizes insoluble soil phosphate and produces plant growth substances in the soil and are environmental friendly playing a significant 
role in crop production. The soil loses its biological dynamism owing to repeated and indiscriminate use of inorganic source of fertilizer. They also help host plants to resist diseases and withstand stress conditions by different mechanism which vary depending upon the type of biofertilizer agent involved. In other words, biofertilizers are based on renewable energy sources and are eco-friendly compared to commercial fertilizers.

\section{Bio-pesticide}

Biopesticides are biological agents in the form of natural enemies or naturally occurring substances for the controlling pests. They include microbial pesticides, mostly usedBacillus thuringiensis, other are plantIncorporated-Protectants (PIPs) and biochemical pesticides like insect sex pheromones. Major advantages are that these are usually inherently no or less toxic than conventional pesticides affecting only the target pest and closely related organisms, quite effective in micro-quantities, quickly kill, moreover some works well on high threshold pests. Traditionally farmers use various plant parts or products for controlling pests or harmful organisms like strong smell of garlic or chilli against any insects, sweet basil as repellent against mosquito and so on. Neem leaves, marigold cultivation, ash application are many such indigenous techniques have gained popularity among the local farmers in different parts of Indian districts (Table 1).

\section{Sustainable fruit production}

The impetus for thinking about sustainable fruit production came from challenges with pest management, particularly the use of insecticides that left a persistent legacy (e.g. lead arsenate), induced new pest outbreaks, or resulted in pesticide resistance. The emergence of integrated control and integrated pest management during the mid $20^{\text {th }}$ century focused on minimizing the unanticipated problems with pesticides and maximizing natural control forces, much like sustainable agriculture's emphasis on internal biological resources. These terms were described as concepts, not fixed techniques. Fruit production faces a whole range of sustainability issues today, spanning all the economic, environmental, and social dimensions mentioned above. For growers of all crops, economic sustainability must be addressed in the short-term or their operation will fail in an unsubsidized system. The economic issues include rising production costs (e.g. labor) with static or declining prices; retail consolidation leading to more sellers than buyers and less economic power for producers; declining demand for some fruits; global competition and counter seasonal production in opposing hemispheres. Environmental issues around pesticides, water use and quality, energy, biodiversity, and air (e.g. methyl bromide) all relate to sustainability, but often on a longer time frame than economics. And social sustainability encompasses worker safety and other labor issues, the health-imparting benefits of fruit in the diet, urbanization and land use changes, and food security. The sustainability issues influencing fruit production will depend on the scale, the marketing channels, and the geographic context of location. A small scale, direct market berry grower will face different challenges than a large scale export oriented apple producer.

\section{Nutritional fruit production}

Public health has to a large extent been coupled to lifestyle patterns including dietary changes and selection of daily food. An increasing problem in both developing and developed countries is the commonly reported change in intake patterns resulting in chronic non-communicable diseases (NCDs-noninfectious or transmissible type of diseases), 
including obesity, cardiovascular diseases, stroke, diabetes etc. Similarly as the intake of sugar and non-essential fats are increasing with the changing lifestyle, nutrient sufficiency in the daily food is decreasing. For a productive life and longevity, sufficient intake of nutrients is essential. Both in the developing and developed world, malnourishment in terms of micronutrients is a large problem, and over three billion people are expected to suffer from such malnourishment. Thus, besides the diseases mentioned above, resulting from a sedentary life-style with a too high intake of sugar and fat, micronutrient deficiency in the food also contributes to lower productivity, learning disabilities and increased mortality rates.

An increased number of recent studies have shown the positive impact of consumption of crop-based foods on human health. Especially intake of fruits and nuts has been found important to prevent cardiovascular diseases and obesity. Several reasons can account for the impact on human health. Firstly, cropbased food is generally low in sugar and fat, especially processed versions, but these food products are also rich in nutritionally beneficial components, e.g., micronutrients and antioxidants or bioactive compounds. Worldwide, nutritional deficiency is known to cause two thirds of all childhood deaths. The main problems in such nutritional deficiency are primarily a too low intake of vitamin A (some carotenoids), iron, and zinc. However, also other micronutrients such as selenium and iodine are known to be of importance in nutrient deficiency, as are other vitamins and bioactive compounds, such as for example vitamin E (tocochromanols) and phenolic compounds.

\section{Recent case studies on organic fruit production}

Mitra et al., (2012) standardized the organic nutrient management protocol of Sardar guava under high density (625 plants per ha) planting. Different organic sources of nutrients (neem cake, vermicompost, farm yard manure and poultry manure) and biofertilizers (Azotobacter and Azospirillium) were tried and results revealed that application of neem cake along with Azotobacter significantly increased yield, fruit size and improve quality of fruit.

Table.1 Some biocontrol agents for pest and diseases in fruit crops are as follows

\begin{tabular}{|c|c|c|}
\hline Fruit crop & Insect pest/ Disease & Bio-control agent \\
\hline \multirow[t]{3}{*}{ 1. Apple } & Wooly apple aphid (Eriosoma lanigerum) & Aphelinus mali \\
\hline & $\begin{array}{l}\text { San Jose scale } \\
\text { (Quadraspidiotus perniciosus) }\end{array}$ & Encarsia perniciosi \\
\hline & Gray mold (Botrytis ruehle) & Pseudomonas fluorescens \\
\hline \multirow[t]{2}{*}{ 2. Mango } & Mango mealy bug (Drosicha mangiferae) & Cryptolaemus montrouzieri \\
\hline & Stem-end rot (Botryodiplodia theobromae) & Trichoderma viride \\
\hline 3. Papaya & Papaya mealybug (Paracoccus marginatus) & Acerophagus papayae \\
\hline \multirow[t]{3}{*}{ 4. Citrus } & Cottony cushion scale (Icerya purchase) & Rodolia cardinalis \\
\hline & Green mold (Penicillium digitatum) & Trichoderma viride \\
\hline & Stem end rot (Botryodiplodia theobromae) & Bacillus subtilis \\
\hline \multirow[t]{2}{*}{ 5. Banana } & Anthracnose (Colletotrichum тиsae) & Trichoderma harzianum \\
\hline & Monilinia rot (Monilinia laxa) & Aureobasidium pullulans \\
\hline
\end{tabular}


Shivakumar et al., (2012) reported in papaya that application of FYM equivalent to 100 per cent recommended dose of nitrogen (154.3 t/ha) gave significantly higher fruit yield of 173.9 t/ha as compared to control with RDF and other organic manure treatments except agrigold equivalent to 100 per cent RDN (33.32 t/ha) and vermicompost, sheep manure and bhumilabha in combination with FYM treatments each equivalent to 50 per cent RDN.

Goswami et al., (2012) conducted an experiment to know the effect of biofertilizers enriched in FYM along with half dose of recommended fertilizers on five year old guava plants cv. Pant Parbhat. They reported that trees grown with half dose of RDF $(250 \mathrm{~g}$ $\mathrm{N}: 195 \mathrm{~g} \mathrm{P}: 150 \mathrm{~g} \mathrm{~K})+50 \mathrm{~kg}$ FYM enriched with $250 \mathrm{~g}$ Azospirillum/tree/year produced maximum annual increase in plant height (0.24 and 0.25$)$, plant spread (0.58 and 0.66 $\mathrm{m})$, trunk diameter $(2.68$ and $2.71 \mathrm{~cm})$ and tree volume $(0.055$ and $0.041 \mathrm{~m} 3)$ during 2007-08 and 2008-09, respectively. Godage et al., (2013) revealed the influences of chemical and biofertilizers on fruit yield of guava cv. Sardar. The treatment of 75 per cent $\mathrm{N}+75$ per cent $\mathrm{P} 2 \mathrm{O} 5+100$ per cent $\mathrm{K} 2 \mathrm{O}+$ Azotobacter $5 \mathrm{ml} /$ tree + PSB 5ml/tree resulted significantly maximum fruit diameter $(10.07 \mathrm{~cm})$, fruit weight $(215.06 \mathrm{~g})$, pulp weight $(193.44 \mathrm{~g})$, tree height $(3.80 \mathrm{~m})$, EastWest tree spread.

Ghosh et al., (2014) investigated that among different organic manures, vermin compost at $20 \mathrm{~kg} /$ tree resulted maximum plant growth (spread and height) with quality fruits in respect of total soluble solids and vitamin $\mathrm{C}$ content but FYM at $40 \mathrm{~kg} /$ tree treated plants produced fruits with maximum total sugar content. However, highest yield and maximum sizeable fruits were obtained when the plants were treated with neem cake at 7.5 $\mathrm{kg} /$ tree in sweet orange.
Devi et al., (2014) showed that in Bombai litchi, combinations with farm yard manure + Azotobacter + phosphorous solubilizers + potash mobilizers recorded higher total soluble solids $\left(17.79^{\circ} \mathrm{Brix}\right)$ and total sugar content (17.57\%), whereas vitamin C content $(53.48 \mathrm{mg} / 100 \mathrm{~g}$ pulp) was higher where a combination of neem cake + Azospirillum + phosphorous solubilizers + potash mobilizers was applied. Organic manures and biofertilizers have a direct role in nitrogen fixation, production of phytohormone-like substances and increased uptake of nutrients and hence quality improvement of fruit characteristics. It is apparent that the soil health improved gradually and after two years the microbial population in soil was markedly improved. The higher microbial population in soil releases many of the nutrients, particularly micronutrients which are normally not available to the tree. This caused increased yield and improved fruit quality.

During the last few decades the global population doubled itself from 3 to 6 billion and it is estimated that by the year 2020, it will reach the 8 billion mark. Food and nutritional security is therefore a serious global concern. Neither conventional farming with inorganic alone nor organic farming only with the use organic input can face this challenge. To meet out the food and nutritional security, organic farming helps to improve the quality of fruit crops.

\section{References}

Devi, H. L., Poi, S. C. and Mitra, S. K. (2014). Organic nutrient management protocol for cultivation of Bombai litchi. Acta Hort, 1029: 215-224.

Food and Agriculture Organization. Organic Agriculture. Available online: http://www.fao.org/unfao/bodies/COAG /COAG15/X0075E.htm\#P99_8218 (accessed on 7 December 2013). 
Ghosh, B., Irenaeus, T. K. S., Kundu, S. and Datta, P. (2014). Effect of organic manuring on growth, yield and quality of sweet orange. Acta Hort, 1024: 121124.

Godage, S. S., Parekh, N. S., Nehete, D. S. and Jagtap, V. M. (2013). Influences of chemical and biofertilizers on growth, flowering, fruit yield and quality of guava (Psidium guajava L.) cv. Allahabad Safeda. Bioinfolet, 10(2A): 480-485.

Goswami, A. K., Lal, S. and Misra, K. K. (2012). Integrated nutrient management improves growth and leaf nutrient status of guava cv. Pant Prabhat. Indian $J$ Hort, 69(2): 168-172.

Heslop-Harrison, J. S. (2005). Introduction. In: Biotechnology of Fruit and Nut Crops (Ed. R. E. Litz). $C A B$ International, London, $U K$. pp. xix.

International Federation of Organic Agriculture Movements (IFOAM). IFOAM International Federation of Organic Agriculture Annual Report 2007; International Federation of Organic Agriculture Movements: Bonn, Germany, 2007.
Klee, H. J. (2010). Improving the flavor of fresh fruits: genomics, biochemistry, and biotechnology. New Phytol, 187: 44-56.

Mitra, S. K., Gurung, M. R. and Pathak, P. K. (2012). Organic nutrient management in high density guava orchard. Acta Hort, 933: 233-238.

Shivakumar, B. S., Dharmatti, P. R. and Channal, H. T. (2012). Effect of organic cultivation of papaya on yield, economics and soil nutrient status. Karnataka J. Agric. Sci., 25 (4): 488492.

United States Department of Agriculture (USDA). Report and Recommendations on Organic Farming; United States Department of Agriculture: Washington, DC, USA, 1980.

Varshney, R. K., Kailash, C., Bansal, K. C., Aggarwal, P. K., Datta, S. K. and Craufurd, P. Q. (2011). Agricultural biotechnology for crop improvement in a variable climate: hope or hype? Trends in Plant Science, 16: 363-371.

Yadav, A. K. (2012) Status of organic agriculture in India, Organic Farming Newsletter, 8(2): 11-14.

\section{How to cite this article:}

Kuldeep Singh, Sunil Kumar, Satyabrata Pradhan and Om Prakash Patidar. 2018. Organic Farming for Sustainable and Nutritional Fruit Production in India: A Review. Int.J.Curr.Microbiol.App.Sci. 7(05): 3033-3039. doi: https://doi.org/10.20546/ijcmas.2018.705.354 